\title{
Socializing from a Distance in a Community Music Ensemble During the COVID-19 Pandemic
}

\section{Brent Rowan}

The New Horizons Band Guelph (NHB) program is a not-for-profit organization that provides music-making opportunities to more than one hundred adults in and around Guelph, Ontario, Canada. Various programs are offered on weekday mornings and afternoons so that retirees make up a large portion of the membership. Members can join any of the groups to learn a new instrument, a new style, or simply have fun socializing with other adults in an open, inclusive, and hospitable environment. The programs consist of concert bands, brass and woodwind ensembles, funk-bucket groups, theory classes, swing bands, and jazz improvisation groups. Most members enrol in two or three different groups, meaning that they are physically, mentally, and socially active in our program two or three times per week.

The positive impact on an adult's overall wellbeing by participation in musical activities has been thoroughly studied (Coffman; Daykin et al.; Hallam \& Creech; Solé et al.). Factors of this impact include increased socialisation and physical activity from going to rehearsals; increased deep breathing as required to play a wind instrument; and increased development of fine motor skills, coordination, and cognition between the hands on an instrument, the eyes reading the music and following a conductor, the ears hearing all of the surrounding sounds, and the brain interpreting how to put it all together-all leading to an increase in mental health.

The COVID-19 pandemic and immediate quarantine measures drastically altered the methods used to create this positive impact. The final nine weeks of our programming were cancelled along with four concerts. As Music Director for the program, I began researching and creating ways to continue engaging with the membership with the intention of keeping our members active in mind, body and spirit.

One of the largest impacts for the NHB members was the unavailability of same-space socialization. Most people can play music on their own in their home; however, some have issues accessing an instrument (percussionists not owning their own timpani, bass drum, etc.) while others live in situations that do not allow for playing music in the home (too "disruptive" in an apartment). Once the cancellation of our rehearsals and concerts was announced, we asked the conductor of each group to compose an email providing repertoire, recordings, practice techniques, and other relevant information to help engage their group members. The immediate goal was to keep the music fresh because we hoped to be back playing together within a few weeks! Some dialogue was created through these e-mails, but it seemed to quickly fizzle out as most people were much more focused on adjusting to life in a pandemic. Our website and social media managers also increased the frequency of their posts in order to offer more information and engagement opportunities.

The main challenge for me was creating new ways to engage with the members. Some responded to e-mail, some did research on their own and asked questions or sought assistance, but a large portion of the NHB membership participate because of the social environment. The mainstream media, public health, and government guidelines were all asking us to "social distance" which, subconsciously, was asking our members not to engage in our heavily socializing activities. I understand the health implications behind the use of the term "socially distance," but this is the wrong terminology for what public health officials needed our population to do to "stop the spread." The correct term would be "physically distance," terminology that was 
used in some contexts later in the quarantine period. A question I am left to ponder is: Would the willingness to engage online have increased if the term "socially distance" had been replaced by "physically distance" from the beginning? I am interested in understanding the impact on our population's mental health when we are asked to isolate ourselves both physically and socially.

Like many organizations, we held our AGM, board meetings, and a few virtual cocktail parties on Zoom, but less than half of the membership were engaged. We explored approximately half a dozen online music-making platforms, mainly focusing on real-time musicking hoping to recreate the mental, physical, and spiritual engagement that occurs when making music together in a room. During this period of exploration, social media became flooded with musical organizations presenting mosaic videos of their groups making music together. The mosaic style of music video production has been around for years and Eric Whitacre's virtual choir, which started in 2009, is an excellent example of this. ${ }^{1}$ While these are excellent productions, the amount of time put into learning the music, recording each video, and editing it together makes these massive projects - even when an understanding of how to use the proper equipment is already in place. For the NHB program our main focus is always on the social aspect of making music together and nowhere on social media did I see anyone talking about how their group was continuing to rehearse. Each trial presented a different challenge and my ability to adapt to technical troubleshooting suddenly became my most important skill as a facilitator. Members who already used platforms like Skype or Facetime-often because of how they had already been connecting to physically distant family members-had more success connecting in the virtual platforms. Many of the members seemed reluctant to try new ways of engaging, perhaps because of fear of the technical challenges, because of life distractions, or due to an unwillingness to change. We are currently conducting a survey to gather information about the reasons for the apparent disengagement as well as looking ahead to collect information about comfort levels around various remote musicking options.

We had the most success with the open-source Jamulus platform even though it was one of the more challenging platforms to set up from a technical standpoint. We chose Jamulus as the main platform for music-making because of its lower latency. For our contexts this was the most important element as it allowed for real-time musicking! I kept a record of who attempted to connect and how technically successful each person was. This data allowed me to start thinking about what kinds of music-making would work best given the instrumentation and musical ability of the membership. In a program that separates members into specific styles and skill levels, this became a huge challenge for me as Music Director.

As indicated in studies by Bayley and Waldron (36-51), adults are often very reliant on following the sheet music and concerned with ideas about playing correctly. My main goal in the NHB program is to help members develop their listening skills. One way I do this is by looking for ways to help participants "get off the page" during the warmup times for each group. Focusing only on the sound each person is making and how those sounds travel around the room helps to develop their ability to become more aware of their own sound and the sounds around them. We started our Jamulus sessions with long-tone exercises with the intention of reminding the members to produce their best sound and listen to their bandmates' sounds. This helped to balance levels and attend to sound quality. While conceptually not different than being in the same physical space, this is a completely different skill set as it has as much to do with microphone placement, quality, and hardware set-up as it does proper breath control, posture, and technique! The online environment presented an entirely new set of technical skills for the members to learn while also focusing on creating music with others. 
Critical Studies in Improvisation / Études critiques en improvisation, Vol. 14, No. 1

There have been considerable learning opportunities for me as Music Director in this new environment. Having never rehearsed virtually before, everything I tried was decided upon depending on who was connected and what seemed to make sense in the moment. While it appeared at first that I would need a completely new set of skills, there were quite a few that were transferable from traditional rehearsals such as listening to the members' sounds, comments, and questions; providing information to help create the music; exercising patience as members learn new concepts; and using humour to maintain an open and positive learning environment. I always feel that the skill I rely on the most is my instinctual improvisational ability, and this was still true in the online environment. I often have a general plan for what will happen in our music-making sessions, but I much prefer to go with the flow, listen to how the members are receiving my ideas/concepts, and react in the most musical, socially helpful, and positive way possible. This is as true on the remote platforms as it is in our rehearsal halls, although I have often wondered what the rapport in the remote platform would be had we not already developed relationships during our time together musicking and socializing in physical rehearsal spaces.

Through this process, I have learned a number of things and discovered a number of unanswered questions. I have learned that I, like many artists, am resilient. But is it resiliency or our nature as creative beings to create something out of what we are given? There has to be an acceptance and understanding of what resources are at hand and what intentions are desired so that we can improvise a solution-this was my experience during the initial stages of the COVID-19 pandemic as Music Director for the NHB program. Our members needed to connect, play music, and socialize and we improvised ways for this to happen given the resources at our disposal. The most frustrating parts had to do with questions of accessibility for the members. Troubleshooting connectivity issues meant some members gave up after becoming too frustrated or were too afraid to even try. Our members' musicking and socializing activities were reduced because of the technical challenges faced with online engagement. I increased my awareness of how fortunate some and how unfortunate other members of our society are. Having the financial means to buy all the right hardware did not mean being able to play; being a skilled musician did not mean being able to play; geographic location sometimes meant not being able to play. There were many factors influencing how we all connected. This became a massive group improvisation where no one really had any experience improvising in this context or had any skills with the tools we were given!

As I search for answers to the following list of questions, I am hopeful that our resiliency and creativity will allow us to continue connecting and deepening our social bonds:

- What skills are needed to engage in remote music-making platforms?

- How is rapport developed in a remote learning experience?

- Why did some people choose not to engage in any of our offerings?

- How do the differences between remote musicking and traditional musicking impact the overall wellbeing of the NHB demographic?

- How will the NHB members adapt to future changes in musicking opportunities?

- Will the pandemic experience alter our membership's understanding of perceived and real barriers?

- How will the pandemic experience inform the development of a meaningful social experience for the NHB demographic? 


\section{Notes}

${ }^{1}$ Video and information on Eric Whitacre's Virtual Choir can be found at https://ericwhitacre.com/the-virtual-choir/about.

\section{Works Cited}

Bayley, Jonathan G., and Janice Waldron. "'It's never too late': Adult Students and Music Learning in One Online and Offline Convergent Community Music School." International Journal of Music Education, vol. 38, no. 1, 2020, pp. 36-51.

Coffman, Don D. "Music and Quality of Life in Older Adults." Psychomusicology: A Journal of Research in Music Cognition, vol. 18, nos. 1-2, 2002, p. 76.

Daykin, Norma, et al. "What Works for Wellbeing? A Systematic Review of Wellbeing Outcomes for Music and Singing in Adults." Perspectives in Public Health, vol. 138, no.1, 2018, pp. 39-46.

Hallam, Susan, and Andrea Creech. "Can Active Music Making Promote Health and Well-being in Older Citizens? Findings of the Music for Life Project." London Journal of Primary Care, vol. 8, no. 2, 2016, pp. 21-25.

Solé, Carme, Melissa Mercadal-Brotons, Sofia Gallego, and Mariangels Riera. "Contributions of Music to Aging Adults' Quality of Life." Journal of Music Therapy, vol. 47, no. 3, 2010, pp. 264-81. 